\title{
The effect of blastomere biopsy on preimplantation mouse embryo development and global gene expression
}

\author{
Francesca E. Duncan, Ph.D. ${ }^{a, b}$, Paula Stein, Ph.D. ${ }^{b}$, Carmen J. Williams, M.D.Ph.D. ${ }^{\text {, }}$, and \\ Richard M. Schultz, Ph.D.b \\ a University of Pennsylvania, Center for Research on Reproduction and Women's Health, Philadelphia, PA \\ 19104, USA \\ b University of Pennsylvania, Department of Biology, Philadelphia, PA 19104, USA \\ c National Institute of Environmental Health Sciences, Research Triangle Park, NC 27709, USA
}

\begin{abstract}
The blastomere biopsy procedure does not affect preimplantation embryo development or global patterns of gene expression in a mouse model of Preimplantation Genetic Testing (PGT). However, zona breaching, which is inherent to the blastomere biopsy procedure, causes significant premature and sometimes abnormal hatching.
\end{abstract}

\section{Keywords}

blastomere biopsy; PGD; PGS; preimplantation embryo; gene expression; microarray; blastocyst; mouse

Preimplantation Genetic Testing (PGT), which encompasses both Preimplantation Genetic Diagnosis (PGD) and Preimplantation Genetic Screening (PGS), is a form of prenatal screening done on embryos conceived through assisted reproductive technology (ART) prior to the initiation of pregnancy to ensure that only select embryos are used for transfer (1). PGD is used to detect single-gene disorders and chromosomal abnormalities, to perform HLA-typing, and to screen for adult and late-onset disorders. PGS is used to screen for common aneuploidies. From a clinical perspective, PGT is successful. By 2004, it was estimated that more than 6,000 PGD cycles were attempted worldwide, resulting in the birth of approximately 1,000 children (2). Furthermore, genetic diagnosis using biopsied blastomeres has a 97\% accuracy rate (3).

PGT is typically performed on human embryos derived from either in vitro fertilization or intracytoplasmic sperm injection (ICSI) followed by extended culture until day 3 postfertilization when the embryos have an average of 6.7 cells (4). PGT requires a highly invasive biopsy procedure that involves 1) incubating embryos in divalent-cation-deficient medium to disrupt cell adhesion, 2) breaching the protective zona pellucida with acid Tyrode's solution, laser drilling, or mechanical force and 3) aspirating one or two blastomeres (5). A widely cited study using human embryos demonstrated that blastomere biopsy at the 8-cell stage do not

\footnotetext{
Address correspondence to: Richard M. Schultz, Ph.D., University of Pennsylvania, Department of Biology, Philadelphia, PA 19104, Tel: 1-(215)-898-7869, Fax: 1-(215)-898-8780, E-mail: E-mail: rschultz@ sas.upenn.edu.

Publisher's Disclaimer: This is a PDF file of an unedited manuscript that has been accepted for publication. As a service to our customers we are providing this early version of the manuscript. The manuscript will undergo copyediting, typesetting, and review of the resulting proof before it is published in its final citable form. Please note that during the production process errors may be discovered which could affect the content, and all legal disclaimers that apply to the journal pertain.
} 
appear to affect preimplantation development, and although embryo metabolism and cell number are reduced, both parameters are proportional to the embryo's reduced cellular mass (6). The effect of the blastomere biopsy procedure on gene expression in the resulting blastocyst has not been examined. In this study we developed a mouse model of the biopsy procedure to determine the effect of various aspects of the procedure (incubation in $\mathrm{Ca}^{2+} / \mathrm{Mg}^{2+}$-free medium (CMF), acid Tyrode's solution treatment, blastomere aspiration), performed individually or in combination, on preimplantation embryo development and global patterns of gene expression.

For studies of preimplantation embryo development, 8-cell embryos were collected from mice at $68 \mathrm{~h}$ post-human chorionic gonadropin (hCG) injection as described previously (7). All animal experiments were approved by the Institutional Animal Use and Care Committee and were consistent with National Institute of Health guidelines. The embryos were then subjected to one of the following five treatments: 1) no treatment (UT), 2) incubation in CMF medium (CMF), 3) acid Tyrode's solution exposure to breach the zona pellucida $(\mathbf{A}), 4)$ incubation in CMF medium followed by acid Tyrode's solution exposure to breach the zona pellucida (CMF $+\mathbf{A})$, or 5) the comprehensive blastomere biopsy procedure (BB). The comprehensive blastomere biopsy procedure was done as outlined below and was modified according to the specific experimental treatment being performed.

Eight-cell embryos with rounded blastomeres and no fragmentation were initially incubated in CMF-Chatot-Ziomek-Brinster medium $(8 ; \mathrm{CZB})$ for $5 \mathrm{~min}$ at $37^{\circ} \mathrm{C}$ in a humidified atmosphere of $5 \% \mathrm{CO}_{2}$ in air to loosen cell-cell contacts and then transferred to CMFDulbecco's Phosphate-Buffered Saline. The biopsies were done on the stage of a Nikon Eclipse TE2000 microscope equipped with Hoffman optics and motorized Eppendorf micromanipulators. No more than three embryos were manipulated outside of the incubator at any time. Embryos were held in place by gentle suction on an Eppendorf Sterile VacuTip holding pipette ( $15 \mu \mathrm{m}$ diameter), and a dual-holder system was used to control the pipette containing acid Tyrode's solution ( $6 \mu \mathrm{m}$ diameter) and the biopsy pipette ( $15 \mu \mathrm{m}$ diameter). The zona pellucida was breached by gentle expulsion of a steady stream of acid Tyrode's solution ( $\mathrm{pH}$ 1.6), and a single blastomere with a clear nucleus was removed by aspiration. Following each respective treatment, embryos were cultured individually in $10 \mu \mathrm{l}$ drops of Potassium Simplex Optimization Medium (KSOM) supplemented with amino acids (Millipore, Billerica, MA) at $37^{\circ} \mathrm{C}$ in a humidified atmosphere of $5 \% \mathrm{CO}_{2}$ in air until $96 \mathrm{~h}$ post-hCG injection. Four replicates of these five experimental groups, each containing 20 embryos, were generated for a total of 20 samples and 400 embryos.

At $96 \mathrm{~h}$ post-hCG injection, embryos in each treatment group were examined by light microscopy and categorized morphologically into the following developmental stages: morula, early blastocyst ( $<50 \%$ cavity), blastocyst ( $>50 \%$ cavity), and expanded blastocyst. The majority of the embryos in each treatment group had formed blastocoel cavities of varying size as was expected by $96 \mathrm{~h}$ post-hCG injection, and the various treatments examined had no significant effect on the developmental distribution of embryos (Figure 1A). Hatching or protrusion of the embryo through the zona pellucida was also documented (Figure 1B). At the time examined, less than $4 \%$ of the embryos in the treatment groups that did not involve a breach in the zona pellucida (UT and CMF) had begun to hatch, whereas between $24 \%$ and $56 \%$ of the embryos that were exposed to acid Tyrode's solution hatched prematurely (Figure 1B). Of interest, $3.8 \%$ (4/106) of the embryos that hatched prematurely also did so abnormally (Figure 1C and 1D). These embryos were limited to those that were exposed to acid Tyrode's solution and were characterized by two distinct blastocoel cavities and what appeared to be a shared inner cell mass (ICM) that spanned the defect in the zona pellucida.

To determine the effect of the various aspects of the blastomere biopsy procedure on global patterns of gene expression, total RNA was extracted from each set of 20 embryos in each 
treatment group at $96 \mathrm{~h}$ post-hCG injection. This total RNA was then used to prepare target cRNA by linear two-round amplification as described previously (9). The final yield of biotinylated cRNA/20 embryos ranged from 34-78 $\mu \mathrm{g}$, of which $20 \mu \mathrm{g}$ was fragmented and submitted to the University of Pennsylvania Microarray Facility where the samples were serially hybridized to the Affymetrix MOE430v2 GeneChip. Quality control parameters for all samples were within the following ranges: scale factor: $0.27-0.47$, percent of genes detected: 44-51\%, actin $3^{\prime} / 5^{\prime}$ signal ratio: $1.5-4.2$, and GAPDH $3^{\prime} / 5^{\prime}$ signal ratio: $3.1-4.3$. The GC-RMA algorithm was used to quantify and normalize microarray signals using Stratagene Array Assist Lite, Version 3.4. The resulting. chp files were imported to GeneSpring (v7.31, Agilent Technologies) where probe sets were filtered to retain those that were flagged as $\mathrm{P}$ (present) in at least 3 of the 20 samples. The data was $\log 2$-transformed and subjected to analysis using Partek Genomics Suite (v6.3, Partek, Inc). A 2-Way Mixed Model ANOVA was performed to identify genes that were differentially expressed between the five treatment groups irrespective of the experiment date. A 4-Way Mixed Model ANOVA was performed to determine if any genes responded to any of the following four factors: experiment date, incubation in CMF medium, acid Tyrode's solution treatment, or aspiration. No statistically significant differences in gene expression were detected. These microarray data have been deposited in the Gene Expression Omnibus (GEO) repository at the National Center for Biotechnology Information (www.ncbi.nlm.nih.gov/geo/; GSE11206).

These results indicate that neither the comprehensive biopsy procedure itself nor its component parts have a significant effect on the developmental stage distribution of the resulting embryos. Although not statistically significant with the number of embryos used in this study, a clear trend exists towards developmental delay between embryos that underwent the blastomere biopsy procedure compared to untreated controls. For example, at $96 \mathrm{~h}$ post-hCG injection, only $16 \%$ of the untreated embryos were morulae compared to $25 \%$ of the biopsied embryos (Figure 1A; compare UT and BB columns). Conversely, fewer biopsied embryos reached the expanded blastocyst stage compared to untreated controls (7.5\% versus $20 \%)$. It is possible that such a delay is associated with reduced developmental competence, although this remains to be proven.

We also observed that zona breaching, common to ART procedures such as assisted hatching and PGT, causes significant premature hatching characterized in approximately $4 \%$ of the embryos by the blastocyst stage with two blastocoel cavities and what looked to be a shared ICM. Because all embryos were ultimately pooled and used for the microarray analysis, we were not able to track the developmental outcome of these specific embryos. We conducted, however, an additional experiment to determine the identity of the cells shared between the two blastocoel cavities. To do this, we performed the blastomere biopsy procedure and allowed the blastocysts to develop until $114 \mathrm{~h}$ post-hCG injection at which time they were fixed and stained using an antibody against the POU transcription factor, OCT-4 (Santa Cruz Biotechnology, Santa Cruz, CA), to label the ICM (10) and Sytox Green (Invitrogen, Carlsbad, CA) to label all nuclei. We observed that in atypically hatching embryos, the nuclei between the two blastocoel cavities were OCT-4 positive, which strongly suggests that they are components of the ICM (Figure 1E-G). Interestingly, an atypically hatching human blastocyst with similar morphology to that observed in this study ultimately divided into two separate blastocysts (11). Thus, the blastomere biopsy technique inherent to PGT may increase the frequency of dichorionic monozygotic twinning. In fact, a case report was recently published that described the formation of dichorionic monozygotic twins following PGS (12). Our results are consistent with previous studies that indicate that there is an association between increased monozygotic twinnng and ART and perhaps specifically with procedures that modify the zona pellucida $(13,14)$. 
Surprisingly, no aspect of the biopsy procedure had a significant effect on global patterns of gene expression in the resulting embryos at the time examined. Although the finding that the embryos in each treatment group are indistinguishable at the gene expression level is reassuring, caution needs to be exercised before concluding that the blastomere biopsy technique is without adverse consequences. First, significant changes may occur at the translational, post-translational or signal transduction level. Second, if only a fraction of the embryos were impacted by the various treatments examined, perturbations in gene expression in these embryos could be masked because pools of embryos were used. Third, the blastomere biopsy procedure was done on embryos that were fertilized and developed in vivo to the 8-cell stage. A greater impact on gene expression might have been observed if the embryos had been derived by assisted reproduction techniques followed by in vitro culture because in vitro fertilization and embryo culture can affect gene expression $(15,16)$. Fourth, the embryos were allowed to develop in culture for $28 \mathrm{~h}$ post-biopsy. Transient and more immediate changes in gene expression could have occurred during this recovery period, and these changes could have significant impact on protein expression. Finally, it is possible that changes in gene expression due to the treatments examined may become manifest later in development.

In this study we developed a mouse model of the clinical procedure of blastomere biopsy to study the effect of this procedure on preimplantation embryo development at a molecular level. The results we report here may differ from that in the human because of key timing differences. We performed the blastomere biopsy procedure on 8-cell mouse embryos, but this procedure is typically performed in the clinic when human embryos have between six and eight cells (4). The mouse embryonic genome, which is activated at the 2-cell stage, is already established at the 8-cell stage (17). This contrasts to the human embryo in which the genome is not activated until between the 4- and 8-cell stage (18). Given these differences in timing of genome activation, the human embryo may be more vulnerable and susceptible to changes in gene expression due to the biopsy procedure.

\section{Acknowledgements}

Funding

This research was supported by a grant from the NIH (U01 HD 44575) to R.M.S, and F.E.D was supported by a training grant from the NIH (T32 HD 007305 22). This work was done in the Department of Biology at the University of Pennsylvania.

This research was supported by a grant from the NIH (U01 HD 4457) to R.M.S. as part of the NICHD Cooperative Program on Female Health and Egg Quality. The authors thank Jock Findlay and Richard Tasca for critically reading the manuscript and their comments, and Karen Schindler, Peter S. Petraitis, and John Tobias for help with the experiments, statistical analyses, and microarray analysis, respectively. F.E.D. was supported by a Training Grant from the NIH (T32 HD 007305 22).

\section{References}

1. Preimplantation genetic testing: a Practice Committee opinion. Fertil Steril 2007;88:1497-1504. [PubMed: 17945219]

2. Verlinsky Y, Cohen J, Munne S, Gianaroli L, Simpson JL, Ferraretti AP, Kuliev A. Over a decade of experience with preimplantation genetic diagnosis. Fertil Steril 2004;82:302-303. [PubMed: 15302274]

3. Braude P, Pickering S, Flinter F, Ogilvie CM. Preimplantation genetic diagnosis. Nat Rev Genet 2002;3:941-953. [PubMed: 12459724]

4. Cohen J, Wells D, Munne S. Removal of 2 cells from cleavage stage embryos is likely to reduce the efficacy of chromosomal tests that are used to enhance implantation rates. Fertil Steril 2007;87:496503. [PubMed: 17141767] 
5. De Vos A, Van Steirteghem A. Aspects of biopsy procedures prior to preimplantation genetic diagnosis. Prenat Diagn 2001;21:767-780. [PubMed: 11559914]

6. Hardy K, Martin KL, Leese HJ, Winston RML, Handyside AH. Human preimplantation development in vitro is not adversely affected by biopsy at the 8-cell stage. Hum Reprod 1990;5:708-714. [PubMed: 2254404]

7. Zeng F, Baldwin DA, Schultz RM. Transcript profiling during preimplantation mouse development. Dev Biol 2004;272:483-496. [PubMed: 15282163]

8. Chatot CL, Ziomek CA, Bavister BD, Lewis JL, Torres I. An improved culture medium supports development of random-bred 1-cell mouse embryos in vitro. J Reprod Fertil 1989;86:679-688. [PubMed: 2760894]

9. Pan H, O’Brien MJ, Wigglesworth K, Eppig JJ, Schultz RM. Transcript profiling during mouse oocyte development and the effect of gonadotropin priming and development in vitro. Dev Biol 2005;286:493-506. [PubMed: 16168984]

10. Palmieri SL, Peter W, Hess H, Scholer HR. Oct-4 transcription factor is differentially expressed in the mouse embryo during establishment of the first two extraembryonic cell lineages involved in implantation. Dev Biol 1994;166:259-267. [PubMed: 7958450]

11. Behr B, Milki AA. Visualization of atypical hatching of a human blastocyst in vitro forming two identical embryos. Fertil Steril 2003;80:1502-1503. [PubMed: 14667890]

12. Taylor DM, Thum M, Abdalla H. Dichorionic triamniotic triplet pregnancy with monozygotic twins discordant for trisomy 13 after preimplantation genetic screening; case report. Fertil Steril. In press

13. Alikani M, Cekleniak NA, Walters E, Cohen J. Monozygotic twinning following assisted conception: an analysis of 81 consecutive cases. Hum Reprod 2003;18:1937-1943. [PubMed: 12923153]

14. Toledo MG. Is there monozygotic twinning after assisted reproduction technology? Aust N Z J Obstet Gynaecol 2005;45:360-364. [PubMed: 16171467]

15. Rinaudo P, Schultz RM. Effects of embryo culture on global pattern of gene expression in preimplantation mouse embryos. Reproduction 2004;128:301-311. [PubMed: 15333781]

16. Giritharan G, Talbi S, Donjacour A, Di Sebastiano F, Dobson AT, Rinaudo PF. Effect of in vitro fertilization on gene expression and development of mouse preimplantation embryos. Reproduction 2007;134:63-72. [PubMed: 17641089]

17. Schultz RM. Regulation of zygotic genome activation in the mouse. Bioessays 1993;15:531-538. [PubMed: 8135766]

18. Braude P, Bolton V, Moore S. Human gene expression first occurs between the four- and eight-cell stages of preimplantation development. Nature 1988;332:456-461. 

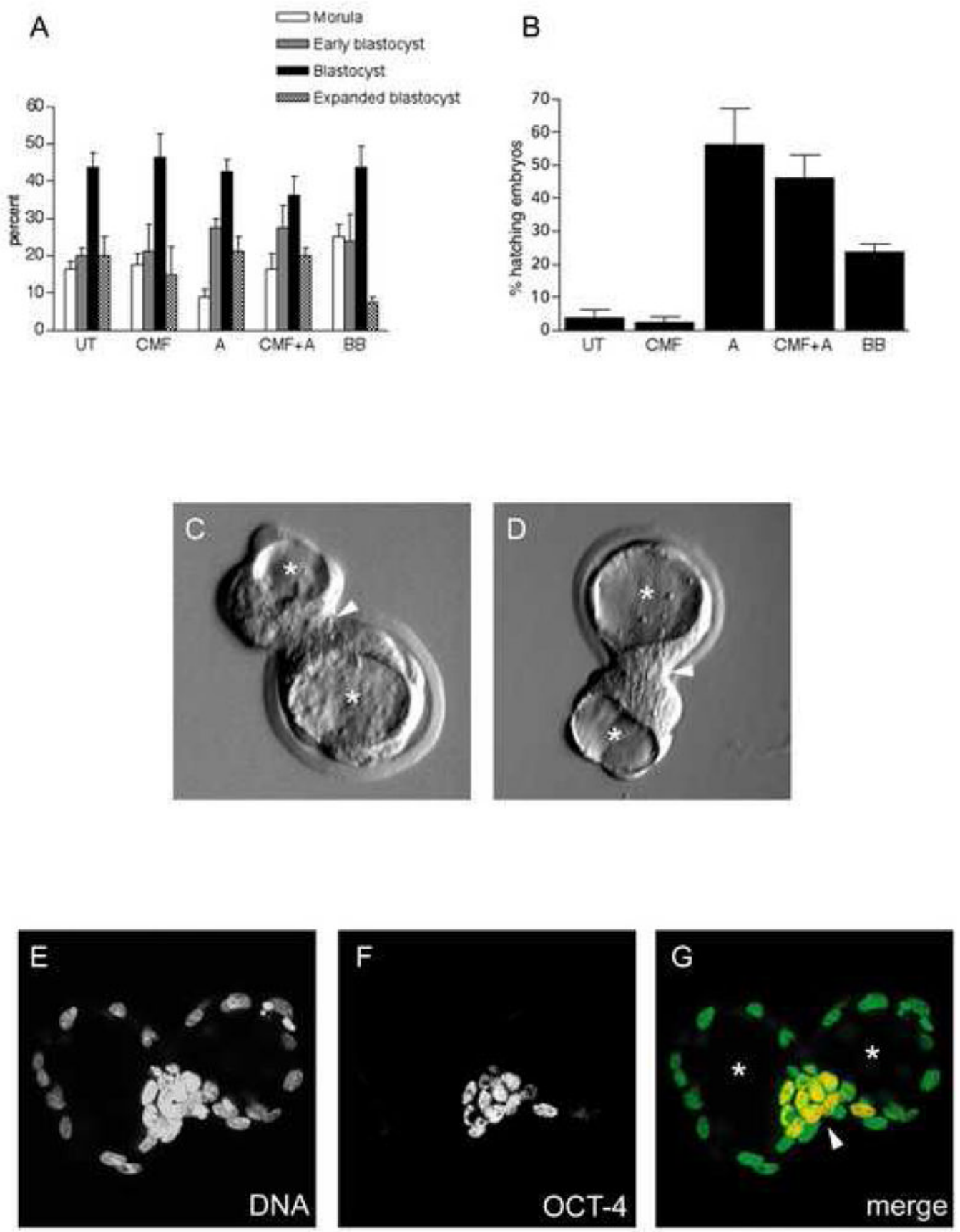

Figure 1.

(A) The developmental stage distribution of embryos in each treatment group at $96 \mathrm{~h}$ post-hCG injection. Probability that the distributions of the stages of development are not significantly different (G-test of independence): Replicate 1: $\mathrm{G}=9.14, \mathrm{df}=12, \mathrm{P}=0.691$; Replicate 2: $\mathrm{G}=11.79, \mathrm{df}=12, \mathrm{P}=0.462$; Replicate 3: $\mathrm{G}=11.34, \mathrm{df}=12, \mathrm{P}=0.500$; Replicate 4: $\mathrm{G}=17.93$, $\mathrm{df}=12, \mathrm{P}=0.118$; Total: $\mathrm{G}=16.43, \mathrm{df}=12, \mathrm{P}=0.172$. (B) The percent of hatching embryos in each treatment group at $96 \mathrm{~h}$ post-hCG injection. Probability that the percent of hatching embryos are not significantly different (G-test of goodness-of-fit): Replicate 1 : $\mathrm{G}=30.70, \mathrm{P}<0.0001$; Replicate 2: $\mathrm{G}=19.45, \mathrm{P}=0.0002$; Replicate 3: $\mathrm{G}=14.53, \mathrm{P}=0.002$; Replicate 4: $\mathrm{G}=23.93$, $\mathrm{P}<0.0001$; Total: $\mathrm{G}=83.61, \mathrm{P}<0.0001$. (C-D) Representative images of abnormal hatching 
observed in treatment groups that involved zona breaching. (E-G) Confocal projections of DNA (E) and OCT-4 (F) immunocytochemistry in an atypically hatching embryo at $114 \mathrm{~h}$ posthCG injection. The merged image is shown in $(\mathrm{G})$. The asterisks highlight blastocoel cavities (2/embryo) and the arrowheads mark the position of shared ICM cells. 